\title{
Tumor Necrosis Factor
}

\author{
Clyde Schultz* \\ Department of Biology University of Calgary, Calgary, Alberta, Canada
}

\begin{abstract}
Tumor Necrosis Factor (TNF) is a soluble cytokine that is found in all mammalian tissues. It is induced in response to stimuli such as trauma, infection, or by the presence of, or in response to an allergen. It is produced by a variety of cell types including neutrophils and macrophages. TNF has the ability to interact with other cytokines and stimulate their production, as well as have a direct effect on tissues that it comes into contact with.
\end{abstract}

\section{Introduction}

TNF also called cachexin or cachectin, is a cell signaling protein that is involved, along with other cytokines in acute phase immunologic reactions. It is produced by a variety of cells, chiefly macrophages and neutrophils but also mast cells, eosinophils and NK cells [1]. TNF's primary roll is in the regulation of immune cells, but it is also a pyrogen and is able to cause fever and inflammation. It can inhibit viral replication and responds to sepsis by inducing Interleukins 1 and 6. It is one of the earliest cytokines that is produced and may have both a direct effect on cells and tissues and an indirect effect of inducing cell types to produce other cytokines.

\section{Structure}

TNF is produced as a type II transmembrane protein arranged as stable homotrimers. It is about 230 amino acids long [2]. It is synthesized as a $26 \mathrm{kD}$ transmembrane monomer. Proteolytic cleavage by ADAM17, a metalloprotease TNF converting enzyme releases solubilized TNF (sTNF) [3]. There is a disassociation of this molecule in concentrations below the nanomolar range thus yielding a pyramid shaped structure of about $17-\mathrm{kD}$. This TNF-alpha of $17-\mathrm{kD}$ is composed of two antiparallel sheets with anti-parallel strands forming a "jelly roll structure", which is somewhat typical for both the TNF family of cytokines, and coincidentally for some viral capsid proteins [4]. Individual monomers will assemble into homotrimers which are non-covalent in nature. The trimers that result resemble a structure wider on top than the bottom.

\section{Function and Cell Signaling}

The tumor necrosis factor receptor superfamily (TNFRSF) is the key component in immune regulation and cell proliferation [5]. There are two receptors that can bind TNF. They are labelled TNFR1 (55 $\mathrm{kDa})$ and TNFR2 $(75 \mathrm{kDa})$. TNFR1 is the more prevalent of the two receptor types and can be found in most tissues. There is a high degree of amino acid similarity between the two receptors which comprise the extracellular regions. There is more homology between the intracellular regions [6]. Both TNFR(s) can be activated by both membrane-bound and soluble trimeric forms of TNF. TNFR2 is found more closely associated with the immune system. In either case, when contact with the ligand occurs TNF receptors form trimers with "groves" formed between the monomeric structure, thus resulting in the receptor undergoing a conformational change [7].

\section{Pathology}

TNF levels in the body are controlled usually by natural mechanisms of the immune systems which "clear" the protein before any damage can be done. However, an excess of TNF triggers inflammation, either local or systemic. Inflammation signs and symptoms include fever, redness, and swelling. It is capable of causing death to a variety of cells ranging from normal to cancer cells. TNF can play a part in cell proliferation, apoptosis, lipid metabolism and coagulation (formation) of blood clots. Since the primary role of TNF is cellular regulation it may respond to or affect sepsis by induction of Interleukins 1 and/or 6 . The presence of TNF in the ocular environment has been linked to neovascularization of the cornea [5]. TNF induction by Gram negative bacterial endotoxin has been shown to be the cause of many systemic side effects of infection by this group of bacteria [8].

Endotoxin or more specifically the Lipid A component of the endotoxin molecule can also cause acute inflammation of the anterior chamber of the eye [9]. This occurs due to the triggering of immune cells such as neutrophils to produce TNF and Interleukin-1. The effects in the ocular environment are pronounced. Signs include swelling, redness and exudate production. There is also extreme sensitivity to light (photophobia).

\section{Treatment}

There are natural levels of TNF in the body, but an excess of TNF can lead to the pathologies discussed above. There are a variety of agents such as TNF inhibitors or blockers, as well as anti-TNF agents. Some of the drugs are Adalimumab, Certolizumab, Entanercept, Golimumab, and Infliximab which are TNF blockers $[10,11]$. They are used reduce joint pain and swelling due to arthritis. These drugs may also be used to treat Crohn's disease and colitis, as well as uveitis of the eye. Blockers interact directly with TNF to prevent binding and thus actions on cells.

Should TNF blockers not work, tofacitinib (marketed as Xeljanz) may be used as a TNF inhibitor [12]. It is a primary treatment for

${ }^{\star}$ Correspondence to: Clyde Schultz, Department of Biology University of Calgary, 2500 University Drive, Calgary, Alberta, Canada, E-mail: schultzc@ucalgary.ca

Received: October 10, 2018; Accepted: October 25, 2018; Published: October 30,2018 
rheumatoid arthritis [13]. Anti-TNF agents of all types have a number of side effects include redness and burning at the injection site. Coughing, headaches, nausea, weakness, and general malaise are also symptoms of the treatments. However, when used they are effective in reducing physiological stress due to excess TNF levels, that may be systemic or occur locally.

\section{Conclusion}

Tumor necrosis factor may be thought of as first among equals as relative to its relationship to other cytokines. This may be considered to be so for a variety of reasons including the time at which it is stimulated, the mode of action of the cytokine itself, and the cells types involved and the pathologies that results. There are a number of therapies that have been developed and are currently used in clinical practice which act as TNF antagonists directly. These have greater or lesser degrees of therapeutic success and also side effects depending on the individual patient. Work on TNF and TNF induced pathogies will continue with the goal of improved and safer therapies.

\section{References}

1. Cawthorn WP, Sethi JK (2008) TNF-alpha and adipocyte biology. FEBS Lett 582: 117131. [Crossref]

2. Kriegler M, Perez C, DeFay K, Albert I, Lu SD (1988) A novel form of TNF/cachectin is a cell surface cytotoxic transmembrane protein: ramifications for the complex physiology of TNF. Cell 53: 45-53.
3. Black RA, Rauch CT, Kozlosky CJ, Peschon JJ, Slack JL, et al. (1997) A metalloproteinase disintegrin that releases tumor necrosis factor alphas from cells. Nature 6618: 729-33. [Crossref]

4. Olszewski MB, Groot AJ, Dastych J, Knol EF (2007) TNF trafficking to human mast cell granules: mature chain-dependent endocytosis. J Immunol 178: 5701-5709. [Crossref]

5. Rosenbaum JT, Howes EL Jr, Rubin RM, Samples JR (1988) Ocular inflammatory effects of intravitreally-injected tumor necrosis factor. American J Path 133: 47-53.

6. Rothe J, Gehr G, Loetscher H, Lesslauer W (1992) Tumor Necrosis Factor ReceptorsStructure and Function. Immunol Res 11: 81-90.

7. Vanamee ÉS, Faustman DL (2018) Structural principles of tumor necrosis factor superfamily signaling. Sci Signal 11: eaao4910. [Crossref]

8. Zou J, Guo P, Lv N, Huang D (2015) Lipopolysaccharide-induced tumor necrosis factor-alpha factor enhances inflammation and is associated with cancer. Mol Med Rep 12: 6399-6404. [Crossref]

9. Schultz CL, Buret AG, Olson ME, Ceri H, Read RR, et al. (2000) Lipopolysaccharide Entry In the Damaged Cornea and Specific Uptake Polymorphonuclear Neutrophils. Infect Immun 68: 1731 .

10. Flood J (2008) Tumor Necrosis Factor (TNF) Inhibitors. Managed Care 17: 2-4.

11. Catrina AI, Trollmo C, af Klint E, Engstrom M, Lampa J, et al. (2005) Evidence that anti-tumor necrosis factor therapy with both etanercept and infliximab induces apoptosis in macrophages but not lymphocytes in rheumatoid arthritis joints: extended report. Arthritis Rheum 52: 6172. [Crossref]

12. Fernandez-Clotet A (2018) Tofacitinib for the treatment of ulcerative colitis. Expert Rev Clin Immunol.

13. Kucharz EJ, Stajszczyk M, Kotulska-Kucharz A, Batko B, Brzosko M, et al. (2018) Tofacitinib in the treatment of patients with rheumatoid arthritis: a position statemen of experts of the Polish Society of Rheumatology. Reumatologia 56: 203-11. [Crossref]

Copyright: $\odot 2018$ Schultz C. This is an open-access article distributed under the terms of the Creative Commons Attribution License, which permits unrestricted use, distribution, and reproduction in any medium, provided the original author and source are credited. 